
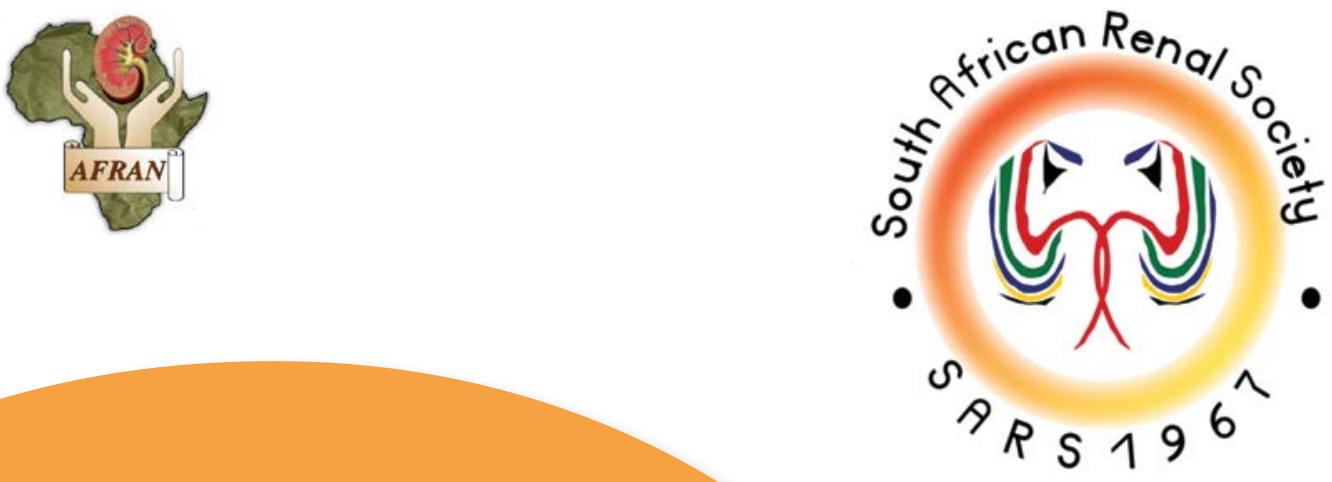

\title{
SOUTH AFRICAN RENAL REGISTRY Annual Report 2015
}




\title{
SCIENTIFIC REPORTS AND GUIDELINES
}

\section{South African Renal Registry Annual Report 2015}

\author{
M Razeen Davids ${ }^{1,2}$, Nicola Marais², Julian C Jacobs ${ }^{2,3}$ \\ 'Division of Nephrology, Stellenbosch University and Tygerberg Hospital, Cape Town, South Africa; ${ }^{2}$ South African Renal Registry; \\ ${ }^{3} \mathrm{~N} I$ City, Goodwood, Cape Town, South Africa.
}

\section{ABSTRACT}

The fourth annual report of the South African Renal Registry summarises the 2015 data on renal replacement therapy (RRT) for patients with end-stage renal disease (ESRD) in South Africa. The South African population increased to 54.96 million in 2015, from 54.00 million in 2014. In December 2015, the number of patients with ESRD who were treated with chronic dialysis or transplantation stood at 10360 , a prevalence of 189 per million population (pmp). The prevalence was 167 pmp in 2013 and 178 pmp in 2014.The increasing prevalence observed is due mainly to the increased numbers of patients accessing haemodialysis in the private sector. In the public sector, which serves $84 \%$ of the South African population, the prevalence of RRT (7I.9 pmp in 2015) remains at levels close to those reported in 1994 so that the disparity in access continues to increase. The disparities between provinces remain, with Limpopo and Mpumalanga the most under-served, as do the disparities between ethnic groups, with Blacks being the most under-served group.

Keywords: renal registry; South Africa; haemodialysis; peritoneal dialysis; transplantation.

\section{INTRODUCTION}

The South African Renal Society has mandated the South African Renal Registry (SARR) to collect, analyse and publish information on the treatment of patients with end-stage renal disease (ESRD) in South Africa. We are pleased to present the fourth annual report of the SARR, which summarises the data on renal replacement therapy (RRT) for patients with ESRD in South Africa as at 31 December 2015.

Once again, we are indebted to all our colleagues as well as the provider companies and their staff for contributing data, and to our sponsors for their continued support. In particular, we appreciate the funding and support received from the National Department of Health.

\section{METHODS}

\section{Registry platform}

Since the inception of the SARR, our technology platform has undergone several major iterations. Our newest version is working well, and has made data entry simpler and faster. The platform has been developed using the Webdev programming environment (www.windev.com) and resides on a secure, dedicated, Windows 10 server at a leading South African internet hosting company. It runs Windows Internet Information Services (IIS) and uses the client/server version of HFSQL (formerly Hyperfile SQL) as its relational database management system. Data capturers interface with the central database via user-friendly web pages and can therefore access the SARR from any device that has internet access and a web browser (Google Chrome is recommended). Password protection ensures that doctors and treatment centres have access to their own data only. Data files are backed up daily using a specialist online backup company. Incremental backups of the registry application are also made daily and the full application is backed up weekly.

Received 19 August 2017; published 01 September 2017.

Correspondence: Razeen Davids, mrd@sun.ac.za.

(C) The Author(s) 2017. Published under a Creative Commons Attribution 4.0 International License. 
The platform is currently being expanded to accommodate the African Renal Registry and allow data capture by other African countries. Thus far, our colleagues in Ghana, Zambia and Burundi have joined the African Renal Registry and have stated entering data using our platform.

\section{Definitions}

ESRD and start date of RRT. ESRD refers to advanced chronic kidney disease (CKD), which is considered to be irreversible and which requires the initiation of renal replacement therapy. The start date is the date of first haemodialysis (HD), the date of the first peritoneal dialysis (PD) flushes or exchanges, or the date of pre-emptive transplantation (where there is no prior dialysis). For patients who are initially thought to have acute kidney injury (AKI) and are dialysed but who do not recover function and are then continued on chronic RRT, the start date is the date of the first dialysis, even though the diagnosis at that time was AKI and not ESRD.

Initial RRT modality. This is the intended first modality and should normally be the modality being used on day 91 of RRT. This means that someone who presents late and who is started on urgent HD but is soon established on PD will have PD recorded as the initial modality.

Changes in the responsible treating unit. This refers to a change in the dialysis unit, PD follow-up unit/clinic, or transplant follow-up unit/centre/practice. A transfer entry in the registry is required to record this. This should not be done for short-term transfers when the intention is that the patient will return to the "home" unit, e.g. for holiday dialysis, temporary transfer to a unit with isolation facilities, etc.

Primary renal diagnosis. Responsible nephrologists/ physicians should assist their data capturers to ensure that this critical information is accurate. We are using the set of renal diagnosis codes of the ERA-EDTA [I] and have mapped all previous entries to these codes. If there is uncertainty about the renal diagnosis, as is often the case with patients who present late, then the primary renal diagnosis should be indicated as "chronic kidney disease (CKD) - aetiology uncertain/unknown”. In patients who present with ESRD, small kidneys and hypertension there should not be an automatic default to labelling such patients as having "chronic glomerulonephritis" or "hypertensive renal disease".

\section{Chronic hypertensive nephropathy or malignant} hypertensive nephropathy. This should be selected as the primary renal diagnosis if there is no reason to suspect that the hypertension is secondary to pre-existing renal disease. We suggest that the following criteria be met: hypertension known to precede renal dysfunction, left ventricular hypertrophy, proteinuria $<2$ g/day, and no evidence of other renal diseases [2,3].

Lost to follow-up. The SARR assumes that a functioning transplant is maintained unless there is evidence of a "transplant failure" or death. A dialysis modality is assumed to continue for one year from the date of the last registry entry, in the absence of evidence of death; thereafter the patient is considered lost to follow-up. Patients are also considered lost to follow-up one year after a "transplant failure" entry if no further entries are recorded.

Recovered renal function. These are patients who have been initiated on chronic HD/PD and who no longer require dialysis. The period of dialysis-free recovery must persist for at least 90 days. If the period of recovery is less than 90 days and dialysis is restarted, there should be no END entry and dialysis is considered to have been continuous. If the period of recovery exceeds 90 days and the patient restarts RRT (even within the same year), there should be an END entry for the initial period of RRT and then a new entry recorded for the patient when he/she starts the second period of RRT, i.e., there will be two registry entries for the same patient.

\section{Ethics approval}

The SARR operates as a longitudinal study with ethics approval from the Health Research Ethics Committee of Stellenbosch University (reference no. NII/0I/028). This is renewed annually upon submission of a progress report. A waiver of individual informed consent has been granted, and the approval includes country-wide data collection on adults and children, public and private sectors, and the tapping of various data sources to improve the accuracy and completeness of data. These include records available through doctors' practices, dialysis and transplant centres, provider companies, and medical aid funds.

\section{RESULTS}

\section{South Africa in 2015}

According to the Stats SA mid-year estimates for 2015 [4], the population of South Africa increased by nearly one million from the previous year to 54.96 million people. There was a slight female predominance (5l.1\%). Black African citizens constituted $80.5 \%$ of the population, with people of mixed ethnicity (Coloured) making up 8.8\%, Whites $8.3 \%$ and Indians/Asians 2.5\%. The province of Gauteng had the largest population, followed by KwaZulu-Natal.

South Africa is classified as an upper-middle income country by the World Bank, with a GNI per capita by the Atlas method (current US\$) of $\$ 6090$ and by the purchasing 
power parity (PPP) method (current international US\$) of $\$ 12$ 900. Most of the population (84\%) relies on the public health sector for services, with only a small proportion (16\%) having medical insurance and accessing private sector healthcare [5].
Life expectancy at birth for 2015 was estimated at 60.6 years for males and 64.3 years for females. The infant mortality rate for 2015 was estimated at 34.4 per I 000 live births. The estimated overall HIV prevalence rate was approximately $11.2 \%$, and 16.6\% for adults aged I5-49 [4].

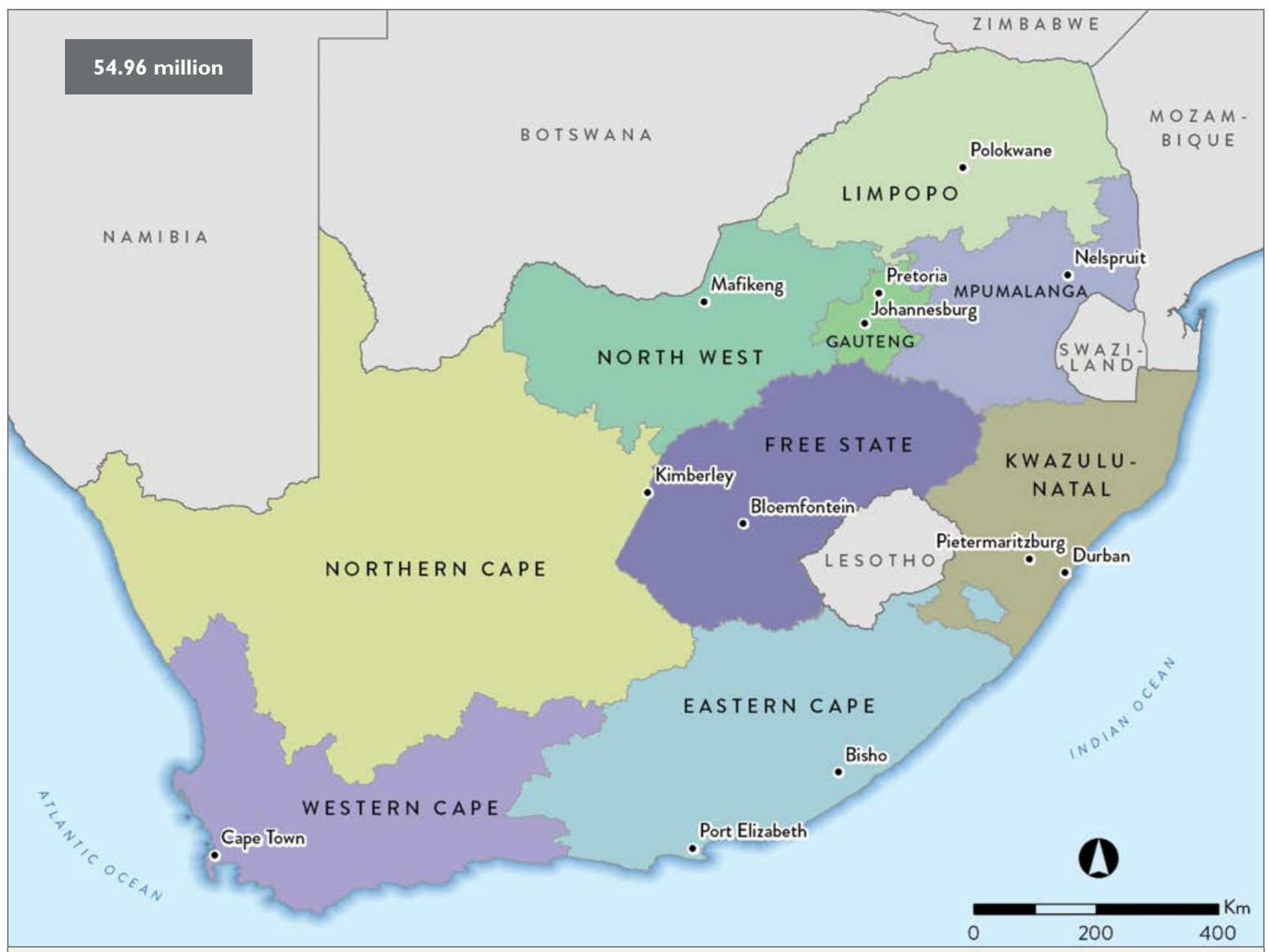

Figure I. Provinces and major cities of South Africa.

Table I. Population data by ethnic group.

\begin{tabular}{|lcc|}
\hline Population group & million & $\%$ \\
\hline Black & 44.23 & 80.5 \\
Coloured & 4.83 & 8.8 \\
Indian/Asian & 1.36 & 2.5 \\
White & 4.53 & 8.3 \\
\hline Total & 54.96 & 100 \\
\hline
\end{tabular}

\begin{tabular}{|lcc|}
\hline \multicolumn{3}{|l|}{ Table 2. Population data by province. } \\
\hline Province & million & $\%$ \\
\hline Eastern Cape (EC) & 6.92 & 12.6 \\
Free State (FS) & 2.82 & 5.1 \\
Gauteng (GT) & 13.20 & 24.0 \\
KwaZulu-Natal (KZN) & 10.92 & 19.9 \\
Limpopo (LP) & 5.73 & 10.4 \\
Mpumalanga (MP) & 4.28 & 7.8 \\
North West (NW) & 3.71 & 6.7 \\
Northern Cape (NC) & 1.19 & 2.2 \\
Western Cape (WC) & 6.20 & 11.3 \\
\hline Total & 54.96 & 100 \\
\hline
\end{tabular}


Treatment centres for dialysis and transplantation

An additional 33 treatment centres, 32 of these in the private sector, contributed data for this 2015 report. The total number of centres in 2015 was 258; 228 (88.4\%) of these were privately owned. One privately owned unit in Limpopo was established as a public-private partnership on the premises of a government hospital to serve public sector patients.

Table 3. Number of centres by province and sector.

\begin{tabular}{|lcccccccccrr|}
\hline Sector & EC & FS & GT & KZN & LP & MP & NW & NC & WC & All \\
\hline Public & 3 & 6 & 7 & 5 & 0 & 0 & 3 & 1 & 5 & 30 \\
Private & 19 & 11 & 69 & 58 & 11 & 10 & 14 & 4 & 32 & 228 \\
\hline Total & 22 & 17 & 76 & 63 & 11 & 10 & 17 & 5 & 37 & 258 \\
\hline
\end{tabular}

\section{Prevalence of renal replacement therapy}

The total number of patients on RRT on 31 December 2015 was 10360 . With a population of 54.96 million, this is a prevalence of 189 per million population (pmp). The prevalence for 2014 was 178 pmp. In 2015, the province with the highest patient numbers was Gauteng, followed by KwaZulu-Natal and the Western Cape, while the province with the highest prevalence was the Western Cape, followed by Gauteng and KwaZulu-Natal.

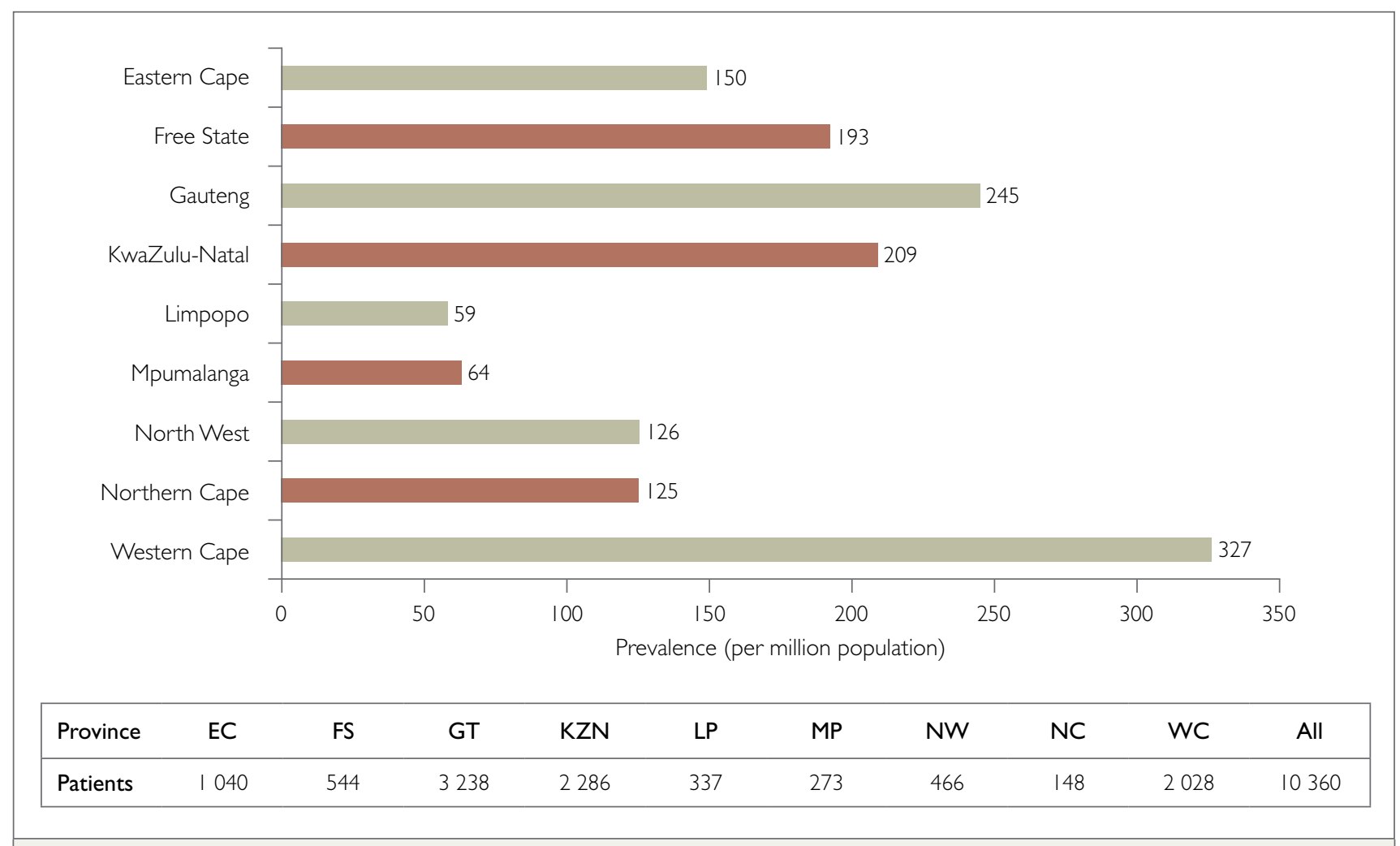


The number of patients treated in the public sector in 2015 remained low, with a prevalence of $71.9 \mathrm{pmp}$. This is lower than the rate of $72.6 \mathrm{pmp}$ reported for 2014 . In the private sector, the rate increased from $716.3 \mathrm{pmp}$ in 2014 to $799.3 \mathrm{pmp}$ in 2015. Denominators for prevalence calculations are based on the Stats SA mid-term estimates [4] and the Council for Medical Schemes Annual Report [5]. Medical aid beneficiaries who are unclassified with respect to province were allocated to provinces in proportion to the numbers of beneficiaries in each province.
Table 4. RRT prevalence by healthcare sector.

\begin{tabular}{|lcc|}
\hline & Public & Private \\
\hline Population in millions & 46.15 & $8.81^{*}$ \\
ESRD patients on treatment & 3318 & 7042 \\
Treatment rate (pmp) & 71.9 & 799.3 \\
\hline
\end{tabular}

"Council for Medical Schemes Annual Report 2015/16

Table 4. Numbers of patients by sector and province.

\begin{tabular}{|c|c|c|c|c|c|c|c|c|c|c|}
\hline Sector & $\mathrm{EC}$ & FS & GT & $\mathrm{KZN}$ & LP & $M P$ & NW & $\mathrm{NC}$ & WC & All \\
\hline Public & 315 & 227 & 958 & 630 & 72 & 17 & $16 \mid$ & 82 & 856 & 3318 \\
\hline Private & 725 & 317 & 2280 & 1656 & 265 & 256 & 305 & 66 & | 172 & 7042 \\
\hline Total & I 040 & 544 & 3238 & 2286 & 337 & 273 & 466 & 148 & 2028 & 10360 \\
\hline
\end{tabular}

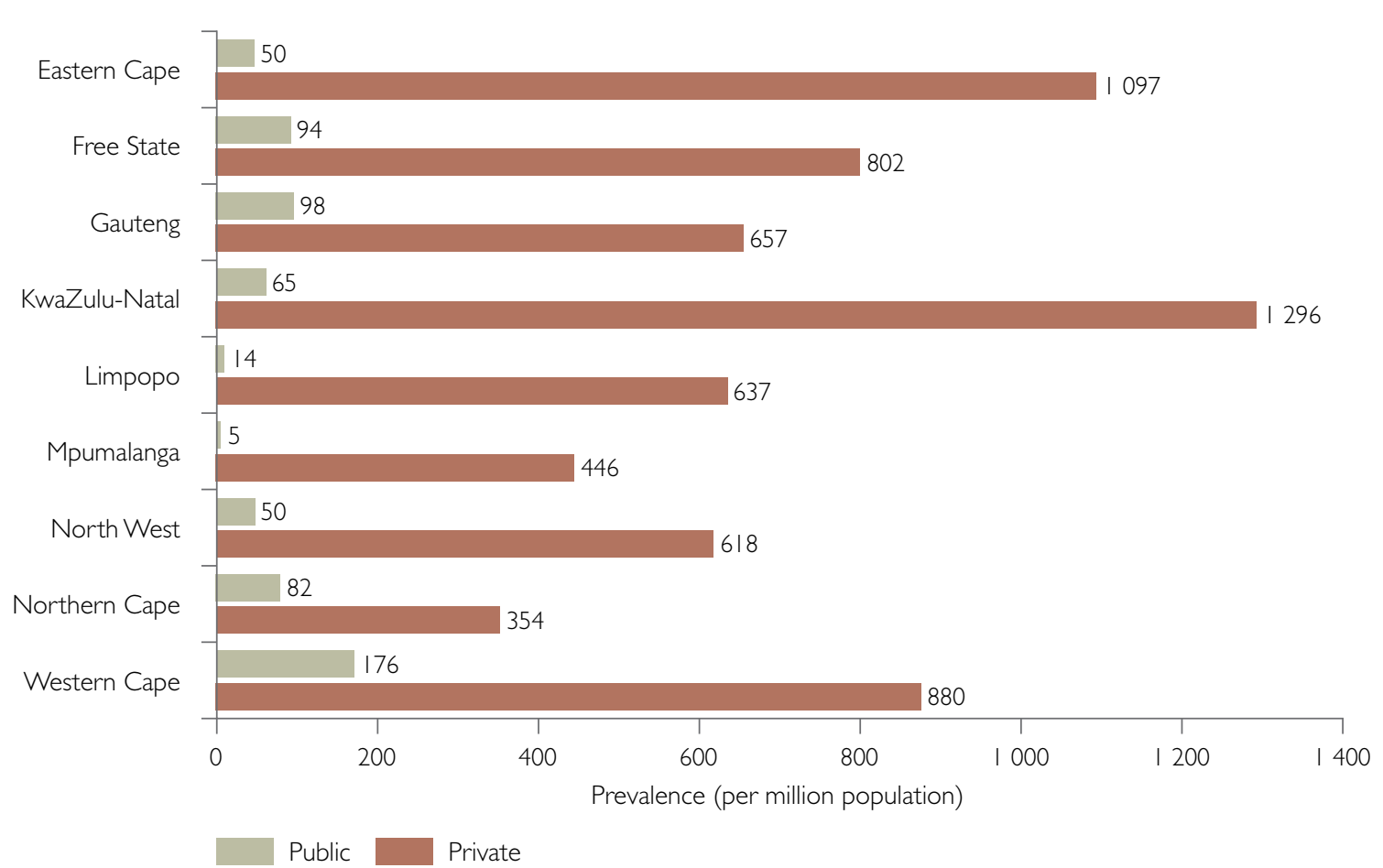

Figure 3. Prevalence of RRT by province and sector. 


\section{Treatment modality}

Of the 10360 patients on RRT in 2015, 13.4\% had a functioning renal transplant. Of the 8969 patients on dialysis, $16.1 \%$ were on peritoneal dialysis and $83.9 \%$ on haemodialysis. Most of the transplant and peritoneal dialysis patients are in the public sector; the private sector has much lower proportions of patients on these RRT modalities.

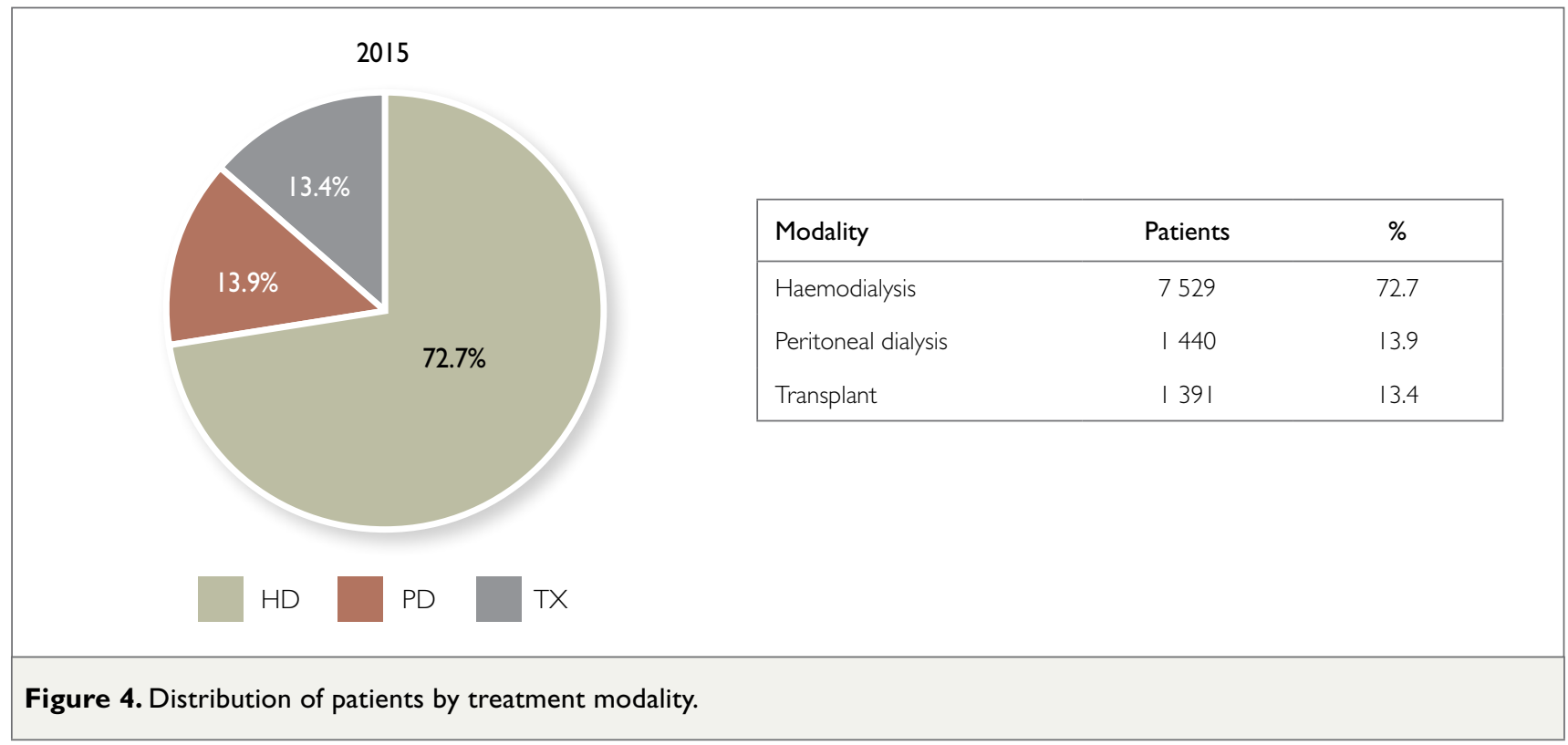

\begin{tabular}{|c|c|c|c|c|}
\hline \multicolumn{1}{|c|}{ PUBLIC } & & & \\
\hline \\
\end{tabular}


Data on new kidney transplants have been supplied by the South African Organ Donor Foundation (http://www.odf.org.za/). The decline in the number of new transplants seen in 2014 (219 transplants) appears to have reversed, with 254 transplants performed in 2015. This included 3 kidney-liver and 3 kidney-pancreas transplants. No transplants were performed in public sector hospitals in the provinces of KwaZulu-Natal and the Free State. The kidney transplant rate for 2015 was 4.6 pmp.

Table 5. New kidney transplants in 2015.

\begin{tabular}{|c|c|c|c|c|c|c|c|}
\hline & \multicolumn{2}{|c|}{ Deceased donor } & \multicolumn{2}{|c|}{ Living related } & \multicolumn{2}{|c|}{ Living unrelated } & \multirow[t]{2}{*}{ Total } \\
\hline & Child & Adult & Child & Adult & Child & Adult & \\
\hline Western Cape - Public & 8 & 34 & 3 & 6 & 0 & 9 & 60 \\
\hline Western Cape - Private & 0 & 19 & 0 & 21 & 0 & 16 & 56 \\
\hline Gauteng - Public & 2 & 32 & 0 & । & 0 & 0 & 35 \\
\hline Gauteng - Private & $5^{*}$ & $45^{*}$ & । & 11 & 0 & 14 & 76 \\
\hline KwaZulu-Natal - Public & 0 & 0 & 0 & 0 & 0 & 0 & 0 \\
\hline KwaZulu-Natal - Private & 0 & 9 & 0 & 9 & 0 & 5 & 23 \\
\hline Free State - Public & 0 & 0 & 0 & 0 & 0 & 0 & 0 \\
\hline Free State - Private & 0 & 4 & 0 & 0 & 0 & 0 & 4 \\
\hline Total & 15 & 143 & 4 & 48 & 0 & 44 & 254 \\
\hline
\end{tabular}

Child $=$ recipient $<18$ years; Adult $=$ recipient 18 years and older

"Includes 2 child and I adult kidney-liver transplants, and 3 adult kidney-pancreas transplants. Data supplied by the SA Organ Donor Foundation.

\section{Demographic and clinical data}

The mean age of the patients on RRT was $51.3 \pm 15.0$ years and $59.3 \%$ were male. Because of the rationing and selection criteria applied in South African public sector hospitals [6], patients treated there are much younger than those treated in the private sector $(43.4 \pm 13.5$ versus $55.0 \pm 14.3$ years). Just more than half of the patients were Black. However, the prevalence was still lowest in Blacks ( 25 pmp) and highest in Indians/Asians (927 pmp).

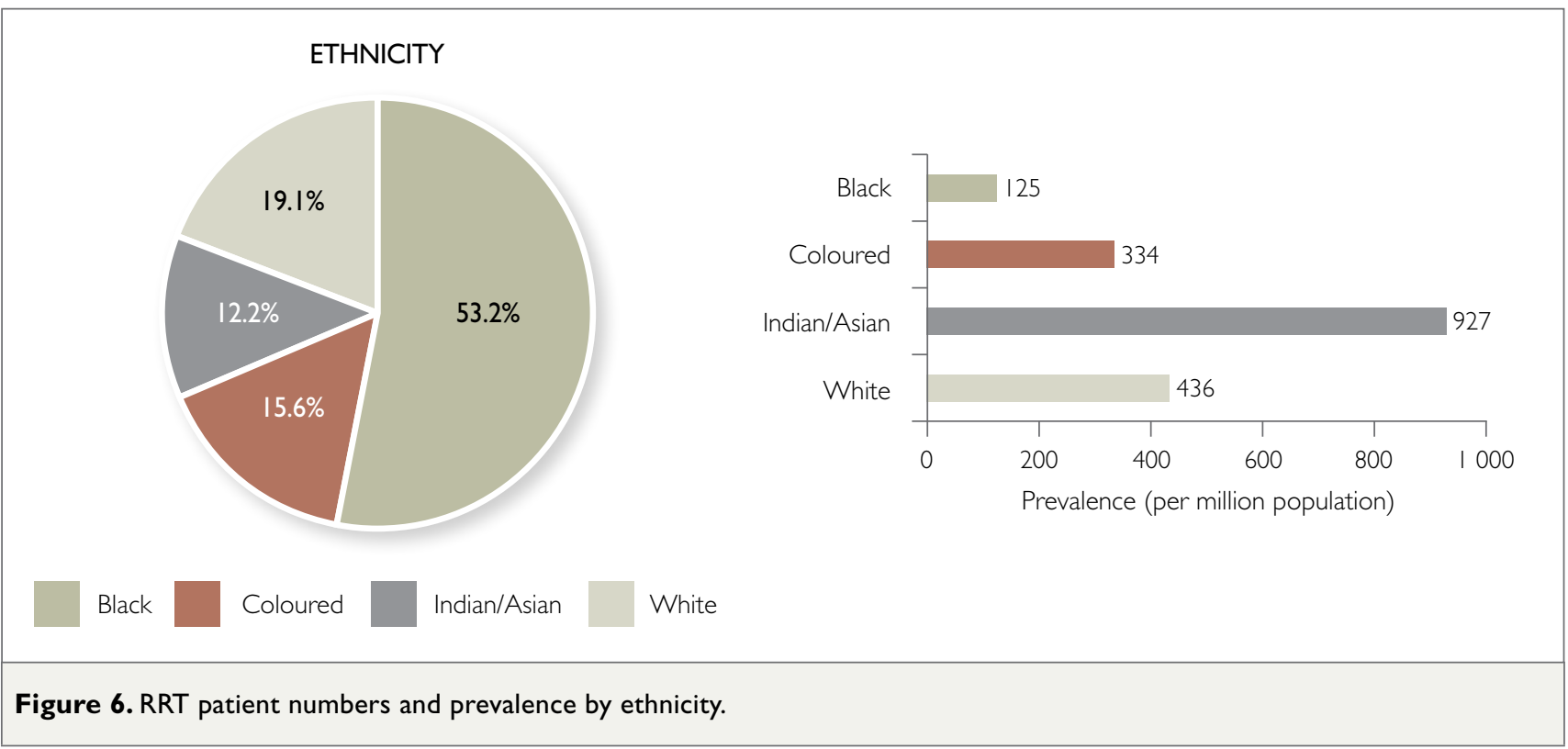


During the 2015 data collection process, we recoded many patients' primary renal diagnoses (PRD) to be in line with the new EDTA-ERA coding system [I]. Taking a conservative approach, we indicated the PRD as "chronic kidney disease/chronic renal failure - aetiology uncertain/ unknown" when it seemed that there was doubt about the diagnosis. For example, because of the links to ICDIO codes in previous versions of the SARR, many patients had a PRD of "chronic renal failure - includes: chronic uraemia, diffuse sclerosing glomerulonephritis" and these had been grouped under glomerular disease. They have now been coded as "uncertain/unknown" and this group is now the largest, followed by hypertensive renal disease and diabetic nephropathy.

Table 6. Most commonly reported causes of ESRD.

\begin{tabular}{|lc|}
\hline & \% of total \\
\hline Uncertain or not stated & 34.1 \\
Hypertensive renal disease & 33.7 \\
Diabetic nephropathy & 14.4 \\
Glomerular disease & 9.5 \\
Cystic kidney disease & 2.9 \\
Obstruction and reflux & 1.5 \\
\hline
\end{tabular}

Of the 8002 patients with data on diabetes status, $51.5 \%$ were diabetic, with a much higher percentage of diabetic patients in the private than in the public sector $(58.0 \%$ versus 38.2\%). These percentages are substantially higher than those we have reported in the past. One reason for this may be that, for this report, we considered patients as diabetic if any previous entry indicated a patient as being diabetic even when the latest annual assessment had an entry for diabetes status as "unknown". We also classified patients as diabetic when the PRD was given as diabetic nephropathy. In addition, we are concerned that data capturers may have found the options for diabetes on our online form confusing and selected "diabetes (type unknown") instead of "unknown" when they were not sure of the diabetes status.

The seropositive rate for hepatitis B virus was 1.3\% (95 of 7056 patients), for hepatitis C virus I. $1 \%$ (65 of 6178 patients) and for HIV $9.4 \%$ (607 of 6464 patients).

\section{DISCUSSION}

The number of patients on RRT in South Africa has continued to increase steadily, and stood at 10360 in December 2015, a prevalence of $189 \mathrm{pmp}$. In 2014, the prevalence was $178 \mathrm{pmp}$. As before, this growth was mainly due to an increase in the number of patients treated with haemodialysis in the private healthcare sector. There is no evidence of any real growth in public sector access to RRT and treatment rates over the past few years remain similar to those seen in 1994. The progressive realisation of access to RRT, which is promised by the South African Constitution, is not happening, and this is cause for great concern.

It is vital that a complete picture of renal replacement therapy across the country is obtained and we therefore need the support of all treatment centres to ensure the inclusion of all patients. Our next round of data collection, for December 2016, is currently under way. Treatment centres should re-check their patients' core data, such as demographic information, the date on which treatment was started, the primary renal diagnosis and diabetes status. Any changes in treatment modality, transfers to another centre, and deaths during the year 2016 need to be recorded.

During the course of the next year we will audit and improve the accuracy of our data on primary renal diagnosis and diabetes status, and we will continue to adapt our platform to accommodate countries that have joined the African Renal Registry initiative.

\section{Acknowledgements}

The SARR is a project of the South African Renal Society (http://www.sa-renalsociety.org/) which is chaired by Prof Razeen Davids and Dr Julian Jacobs.

We thank the following for contributing to the success of our 2015 data collection and annual report:

The doctors, nurses, technologists, support staff and management of participating treatment centres - these centres are listed in Appendix I.

Funding and logistical support was received from:

- National Department of Health

- Actor Pharma

- Adcock Ingram Critical Care (Renal Division)

- Amgen

- Janssen Pharmaceutica

- National Kidney Foundation of South Africa

- National Renal Care

- Roche Pharmaceuticals

- Stellenbosch University 
Our national data manager, Nicola Marais, and data capturer, Suzan Baloyi.

\section{Supplementary materials}

The figures in this report are available as PowerPoint slides via the supplementary materials.

\section{Usage of this report}

Extracts from this report, and the accompanying PowerPoint slides, may be freely used and reproduced without permission provided the source is acknowledged. Suggested citation: Davids MR, Marais N, Jacobs JC. South African Renal Registry Annual Report 2015. African Journal of Nephrology. 2017; 20(1):201-213. Previous reports are available at http://www.sa-renalsociety.org/ registry.asp.

\section{Conflict of interest}

None to declare.

\section{REFERENCES}

I. Venkat-Raman G, Tomson CR, Gao Y, Cornet R, Stengel B,

Gronhagen-Riska C, et al. New primary renal diagnosis codes for the ERA-EDTA. Nephrol Dial Transplant. 2012; 27:44|4-4419.

2. Perneger TV, Whelton PK, Klag MJ, Rossiter KA. Diagnosis of hypertensive end-stage renal disease: effect of patient's race. Am J Epidemiol. 1995; 141:10-15.

3. Schlessinger SD, Tankersley MR, Curtis JJ. Clinical documentation of end-stage renal disease due to hypertension. Am J Kidney Dis. 1994; 23:655-660.

4. Mid-year population estimates, 20I5. Pretoria, South Africa: Stats SA.

5. Council for Medical Schemes Annual Report 20I5/16. Pretoria, South Africa: Council for Medical Schemes.

6. Moosa MR, Maree JD, Chirehwa MT, Benatar SR. Use of the "Accountability for Reasonableness" approach to improve fairness in accessing dialysis in a middle-income country. PLoS ONE. 2016; | l:e0164201. 


\section{APPENDIX I: PARTICIPATING TREATMENT CENTRES}

\begin{tabular}{lll}
\hline EASTERN CAPE & & \\
\hline Public & Private & Private \\
\hline Frere Hospital & Jeffreys Bay Kidney and Dialysis Centre (FMC) & NRC Port Elizabeth HD \\
Livingstone Hospital & Life East London Private Hospital & NRC Port Elizabeth PD \\
Nelson Mandela Academic Hospital & Life New Mercantile Hospital & NRC Queenstown \\
& NRC Butterworth & NRC Vitenhage \\
& NRC East London HD & Port Elizabeth Kidney and Dialysis Centre (FMC) \\
& NRC East London PD & Regional Renal Services Harding \\
& NRC King Williamstown & Regional Renal Services Lusikisiki \\
& NRC Kwadwesi & Regional Renal Services Matatiele \\
& NRC Mdantsane & Regional Renal Services Mthatha \\
\end{tabular}

\begin{tabular}{|c|c|c|}
\hline \multicolumn{3}{|l|}{ FREE STATE } \\
\hline Public & Private & Private \\
\hline Boitumelo Regional Hospital (Kroonstad) & B. Braun Avitum Bethlehem (Hoogland) & NRC Bloemfontein PD \\
\hline Bongani Regional Hospital (Welkom) & B. Braun Avitum Bloemfontein & NRC Kroonstad \\
\hline Dihlabeng Regional Hospital (Bethlehem) & B. Braun Avitum Welkom & NRC Pelonomi \\
\hline Mofumahadi Manapo Mopeli Hospital (Qua Qua) & Bloemfontein Kidney and Dialysis Centre (FMC) & Sasolburg Kidney and Dialysis Centre (FMC) \\
\hline Pelonomi Regional Hospital & Life Rosepark Hospital & Universitas Private Hospital \\
\hline Universitas Academic Hospital & NRC Bloemfontein HD & \\
\hline \multicolumn{3}{|l|}{ GAUTENG } \\
\hline Public & Private & Private \\
\hline Charlotte Maxeke Johannesburg Academic Hospital & Arcadia Kidney and Dialysis Centre (FMC) & Life Groenkloof Hospital \\
\hline Chris Hani Baragwanath Hospital & B. Braun Avitum Lakeview (Benoni) & Life The Glynnwood Hospital \\
\hline Dr George Mukhari Hospital & B. Braun Avitum Pretoria (Kloof) & Life Wilgeheuwel Hospital \\
\hline Helen Joseph Hospital & B. Braun Avitum Pretoria (Urology Hospital) & Morningside Children's Kidney Treatment Centre \\
\hline Leratong Hospital & B. Braun Avitum Sandton & Morningside Kidney and Dialysis Centre (FMC) \\
\hline Sebokeng Hospital & B. Braun Avitum Vanderbijlpark (Emfuleni) & Morula Kidney and Dialysis Centre (FMC) \\
\hline \multirow[t]{17}{*}{ Steve Biko Academic Hospital } & B. Braun Avitum Vereeniging (Midvaal) & Naledi Kidney and Dialysis Centre (FMC) \\
\hline & Baobab Kidney Care - Randburg Dialysis & Netcare Transplant Centre Garden City Hospital \\
\hline & Edison Hammanskraal Centre & Netcare Transplant Centre Jakaranda Hospital \\
\hline & Edison Mamelodi Centre & Netcare Transplant Centre Milpark Hospital \\
\hline & Fordsburg Kidney and Dialysis Centre (FMC) & NRC Akasia \\
\hline & Groenkloof Kidney and Dialysis Centre (FMC) & NRC Alberton \\
\hline & Harmelia Kidney and Dialysis Centre (FMC) & NRC Arcadia \\
\hline & Heidelberg Medical Centre Renal Unit & NRC Johannesburg PD \\
\hline & Hibiscus Kidney and Dialysis Centre (FMC) & NRC Krugersdorp \\
\hline & Izinso Soshanguwe Clinic & NRC Lenasia (Lenmed) \\
\hline & Kempton Kidney and Dialysis Centre (FMC) & NRC Lenasia South (Daxina) \\
\hline & Lenasia Kidney and Dialysis Centre (FMC) & NRC Linksfield \\
\hline & Lesedi Kidney and Dialysis Centre (FMC) & NRC Lyttleton \\
\hline & Life Bedford Gardens Hospital & NRC Mayfair \\
\hline & Life Brenthurst Hospital & NRC Montana \\
\hline & Life Carstenhof Hospital & NRC Mulbarton \\
\hline & Life Fourways Hospital & NRC Olivedale \\
\hline
\end{tabular}

FMC $=$ Fresenius Medical Care, MRC $=$ Melomed Renal Care, NRC $=$ National Renal Care, LRC $=$ Lenmed Renal Centre 
APPENDIX I: PARTICIPATING TREATMENT CENTRES continued

\begin{tabular}{lll}
\hline GAUTENG cont. & & \\
\hline Public & Private & Private \\
\hline & NRC Parktown West & Renalworx Pretoria West \\
& NRC Pretoria East & Renalworx Wilgers \\
& NRC Pretoria PD & Sunshine Dialysis Unit \\
& NRC Rynfield & Tshepo-Themba Kidney and Dialysis Centre (FMC) \\
& NRC Sebokeng & Tshwane Kidney and Dialysis Centre (FMC) \\
& NRC Sedibeng & Vaal Kidney and Dialysis Centre (FMC) \\
& NRC Sunninghill & Vosloorus Kidney and Dialysis Centre (Clinix) \\
& NRC Sunward Park & Waverley Kidney and Dialysis Centre (FMC) \\
& NRC Waterfall & Westrand Kidney and Dialysis Centre (FMC) \\
& Pretoria Kidney and Dialysis Centre (FMC) & Wits Donald Gordon Kidney and Dialysis Centre (FMC) \\
& Randfontein Kidney and Dialysis Centre (FMC) & Wits Donald Gordon Medical Centre Transplant Division \\
& Randfontein Private Hospital Dialysis Unit & \\
\hline
\end{tabular}

\begin{tabular}{|c|c|c|}
\hline \multicolumn{3}{|l|}{ KWAZULU-NATAL } \\
\hline Public & Private & Private \\
\hline Addington Hospital & B. Braun Avitum Dundee & Mount Edgecombe Kidney and Dialysis Centre (FMC) \\
\hline Greys Hospital & B. Braun Avitum Howick & Netcare Transplant Centre St Augustine's Hospital \\
\hline Inkosi Albert Luthuli Hospital & B. Braun Avitum Newcastle & Newcastle Kidney and Dialysis Centre (FMC) \\
\hline King Edward VIII Hospital & B. Braun Avitum Pietermaritzburg & NRC Athlone \\
\hline \multirow[t]{25}{*}{ Ngwelezana Hospital } & B. Braun Avitum Scottburgh & NRC Ballito \\
\hline & B. Braun Avitum Vryheid & NRC Berea \\
\hline & Chatsworth Kidney and Dialysis Centre (FMC) & NRC Chatsworth \\
\hline & Coastal Nephrology Centre Greytown & NRC Durban PD \\
\hline & Coastal Nephrology Centre Nongoma & NRC Gateway \\
\hline & Coastal Neprology Centre Ulundi & NRC Hillcrest \\
\hline & Dr Parag and Raghubir Kidney Care Centre & NRC Ladysmith \\
\hline & Durban Kidney and Dialysis Centre (FMC) & NRC Margate \\
\hline & Ekuphileni Renal Centre Manguzi & NRC Pietermaritzburg CBD \\
\hline & Empangeni Kidney and Dialysis Centre (FMC) & NRC Pietermaritzburg PD \\
\hline & Ethekwini Kidney and Dialysis Centre (FMC) & NRC Pinetown \\
\hline & Kokstad Kidney and Dialysis Centre (FMC) & NRC Richards Bay \\
\hline & Kwazulu Dialysis Chatsmed Renal Unit & NRC Umhlanga \\
\hline & Kwazulu Dialysis Shifa Renal Unit & Pinetown Kidney and Dialysis Centre (FMC) \\
\hline & Kwazulu Dialysis Umlazi Megacity Renal Unit & Port Shepstone Kidney and Dialysis Centre (FMC) \\
\hline & Kwazulu Dialysis Westville Renal Unit & Renal Care Team Durdoc \\
\hline & Life Chatsmed Hospital & Renal Care Team Kwamashu \\
\hline & Life Empangeni Hospital & Renomed Verulam Dialysis \\
\hline & Life Entabeni Hospital & Richards Bay Kidney and Dialysis Centre (FMC) \\
\hline & Life Hilton Hospital & Stanger Kidney and Dialysis Centre (FMC) \\
\hline & Life Mount Edgecombe Hospital & Ultra Kidney Care Isipingo \\
\hline & Life Westville Hospital & Umhlanga Kidney and Dialysis Centre (FMC) \\
\hline & Merediac Durdoc & Verulam Dialysis Centre \\
\hline & Merediac Pinetown & Victoria Kidney and Dialysis Centre (FMC) \\
\hline & Mount Edgecombe DCG & Vryheid Kidney and Dialysis Centre (FMC) \\
\hline
\end{tabular}

FMC = Fresenius Medical Care, MRC = Melomed Renal Care, NRC = National Renal Care, LRC $=$ Lenmed Renal Centre 
APPENDIX I: PARTICIPATING TREATMENT CENTRES continued

\begin{tabular}{lll}
\hline LIMPOPO & & \\
\hline Public & Private & Private \\
\hline & B. Braun Avitum Louis Trichardt & Edison Thohoyandou Centre \\
& B. Braun Avitum Mokopane & NRC Polokwane \\
& B. Braun Avitum Polokwane & NRCVenda Kidney Centre Thohoyandou \\
& B. Braun Avitum Tzaneen & Polokwane Kidney and Dialysis Centre (FMC) \\
& Chantel Van Rooyen Private & \\
& Edison Giyani Centre &
\end{tabular}

\begin{tabular}{lll}
\hline MPUMALANGA & & \\
\hline Public & Private & Private \\
\hline & B. Braun Avitum Ermelo & Hazyview Dialysis Centre \\
& B. Braun Avitum Nelspruit & Life Midmed Hospital \\
& B. Braun Avitum Trichardt & Middelburg Kidney and Dialysis Centre (FMC) \\
& B. Braun Avitum Witbank & Mpumalanga Kidney and Dialysis Centre (FMC) \\
& Emalahleni Kidney and Dialysis Centre (FMC) & NRC Nelspruit \\
\hline NORTHWEST & & \\
\hline Public & Private & \\
\hline Job ShimankanaTabane Hospital & B. Braun Avitum Vryburg & Private \\
Klerksdorp Hospital & Brits Kidney and Dialysis Centre (FMC) & North West Dialysis Lichtenburg \\
Mafikeng Hospital & Carletonville Kidney and Dialysis Centre (FMC) & NRC Rustenberg \\
& Izinso Dialysis Mafikeng & NRC Rustenberg PD \\
& Mafikeng Kidney and Dialysis Centre (FMC) & Potchefstroom Kidney and Dialysis Centre (FMC) \\
& North West Dialysis Hartswater & Rustenburg Kidney and Dialysis Centre (FMC) \\
& North West Dialysis Klerksdorp & Zeerust Renal Unit \\
\hline
\end{tabular}

\begin{tabular}{lll}
\hline NORTHERN CAPE & & \\
\hline Public & Private & Private \\
\hline Kimberley Hospital & B. Braun Avitum Kimberley & NRC Kimberley \\
& B. Braun Avitum Upington & NRC Kimberley PD \\
\hline
\end{tabular}

\begin{tabular}{lll}
\hline WESTERN CAPE & & \\
\hline Public & Private & Private \\
\hline George Hospital & Athlone Kidney and Dialysis Centre (FMC) & NRC Blaauwberg \\
Groote Schuur Hospital & B. Braun Avitum Cape Gate & NRC Cape Town CBD \\
Red Cross War Memorial Children's Hospital & B. Braun Avitum Mossel Bay & NRC Cape Town PD \\
Tygerberg Hospital & B. Braun Avitum Oudtshoorn & NRC George \\
Worcester Hospital & B. Braun Avitum Worcester & NRC Goodwood \\
& Cape Town Kidney and Dialysis Centre (FMC) & NRC Kuilsriver \\
& George Kidney and Dialysis Centre (FMC) & NRC Paarl \\
& Hermanus Kidney and Dialysis Centre (FMC) & NRC Plumstead \\
& Life Knysna Hospital & NRCVredenburg \\
& Life Vincent Pallotti Hospital & Paardevlei Kidney and Dialysis Centre (FMC) \\
& Life Vincent Pallotti Hospital Paediatrics & Panorama Kidney and Dialysis Centre (FMC) \\
MRC Gatesville HD & Rondebosch Dialysis Centre \\
& MRC Gatesville PD & Stellenbosch Kidney and Dialysis Centre (FMC) \\
& MRC Mitchells Plain & UCT Kidney and Dialysis Centre (FMC) \\
& MRC Tokai & UCT Private Academic Hospital \\
Netcare Christiaan Barnard Memorial Hospital & Winelands Kidney and Dialysis Centre (FMC) \\
\hline
\end{tabular}


APPENDIX I: PARTICIPATING TRANSPLANT CENTRES

\begin{tabular}{|c|c|}
\hline \multicolumn{2}{|l|}{ FREE STATE } \\
\hline Public & Private \\
\hline Universitas Academic Hospital & Universitas Private Hospital \\
\hline \multicolumn{2}{|l|}{ GAUTENG } \\
\hline Public & Private \\
\hline Charlotte Maxeke Johannesburg Academic Hospital & Netcare Garden City Hospital \\
\hline \multirow[t]{2}{*}{ Steve Biko Academic Hospital } & Netcare Milpark Hospital \\
\hline & Wits Donald Gordon Medical Centre \\
\hline \multicolumn{2}{|l|}{ KWAZULU-NATAL } \\
\hline Public & Private \\
\hline Inkosi Albert Luthuli Hospital & Netcare St Augustine's Hospital \\
\hline \multicolumn{2}{|l|}{ WESTERN CAPE } \\
\hline Public & Private \\
\hline Groote Schuur Hospital & Netcare Christiaan Barnard Memorial Hospital \\
\hline Red Cross War Memorial Children's Hospital & UCT Private Academic Hospital \\
\hline Tygerberg Hospital & \\
\hline
\end{tabular}

